\title{
Taking advantage of drug resistance, a new approach in the war on cancer
}

\author{
Liqin Wang, Rene Bernards (ه)
}

Division of Molecular Carcinogenesis, Oncode Institute, The Netherlands Cancer Institute, Plesmanlaan 121, 1066 CX Amsterdam, The Netherlands

(C) The Author(s) 2018. This article is published with open access at link.springer.com and journal.hep.com.cn

\begin{abstract}
Identification of the driver mutations in cancer has resulted in the development of a new category of molecularly targeted anti-cancer drugs. However, as was the case with conventional chemotherapies, the effectiveness of these drugs is limited by the emergence of drug-resistant variants. While most cancer therapies are given in combinations that are designed to avoid drug resistance, we discuss here therapeutic approaches that take advantage of the changes in cancer cells that arise upon development of drug resistance. This approach is based on notion that drug resistance comes at a fitness cost to the cancer cell that can be exploited for therapeutic benefit. We discuss the development of sequential drug therapies in which the first therapy is not given with curative intent, but to induce a major new sensitivity that can be targeted with a second drug that selectively targets the acquired vulnerability. This concept of collateral sensitivity has hitherto not been used on a large scale in the clinic and holds great promise for future cancer therapy.
\end{abstract}

Keywords cancer; drug resistance; genetic screens; senescence; targeted therapy

\section{Introduction}

The various cancer genome sequencing projects have yielded profound insights into the mutations that contribute to malignant growth in the various human tissues. An important insight with relevance to therapy from this work is that the major oncogenic "driver" mutations in specific cancers often create a dependency on the signaling pathway that is affected by the mutation. This phenomenon of "oncogene addiction" forms the basis of nearly all targeted cancer therapies today [1]. The clinically most successful examples include the use of BRAF inhibitors in $B R A F^{V 600 E}$ mutant melanomas, the use of ABL kinase inhibitors in $B C R-A B L$ translocated chronic myeloid leukemia, the use of trastuzumab in HER2-amplified breast cancer, and use of EGFR inhibitors in EGFR mutant lung cancer [2]. The use of targeted drugs in these patients often results in a significant increase of progression-free survival, but this improvement does not necessarily translate into a meaningful overall survival, as acquired resistance to these drugs almost invariably develops. We

Received January 24, 2018; accepted April 26, 2018

Correspondence: Rene Bernards, r.bernards@nki.nl discuss here new strategies to improve outcomes for cancer patients that take advantage of the development of drug resistance rather than trying to avoid it.

\section{Avoiding resistance to targeted cancer drugs}

The clinical use of targeted cancer therapeutics has been modeled primarily on the decades-long experience with chemotherapies. Two strategies have emerged from the use of chemotherapies. First, drugs need to be given at maximum tolerated dose to be effective. Second, chemotherapies need to be combined to avoid resistance development. The combinations of chemotherapies that are given for each cancer type have been determined mostly through empirical "trial and error" methods. The major underlying rationale used to identify effective chemotherapy combinations is that drugs that act through different mechanisms are less likely to yield cross-resistance to other drugs. With the advent of targeted therapies and with the development of detailed insights how signaling pathways are connected, it has become possible to develop more rational combinations of targeted therapies. Examples of this include the "vertical targeting" of the BRAF 
and MEK kinases in BRAF mutant melanoma. This approach is based on the insight that resistance to BRAF inhibitors is frequently caused by re-activation of MAPkinase pathway signaling [2]. This suggested that a more powerful blockade of this pathway with two drugs would lead to more effective pathway suppression. Indeed, the combination of BRAF and MEK inhibition is effective in the clinic in slowing the progression of $B R A F$ mutant melanomas [3-5].

The question of which drug combination is the most effective to treat a given cancer is sometimes less straightforward. For instance, the oncogene addiction model would predict that all $B R A F$ mutant cancers will respond to BRAF inhibitors. However, in the case of $B R A F$ mutant colon cancer, this turned out to be incorrect in that hardly any patients responded to BRAF inhibitors [6]. In situations where the best drug combination cannot be readily predicted, functional genetic screens can serve as a powerful platform to investigate in an unbiased way which combinations of pathway inhibitions are particularly effective in killing the cancer cells. This is referred to as "synthetic lethality" genetic screens. Synthetic lethality refers to a situation in which the inactivation of two genes individually is not lethal to a cell, but the combination of the two genes is lethal [7] (Fig. 1). Synthetic lethality

\section{Synthetic lethality}
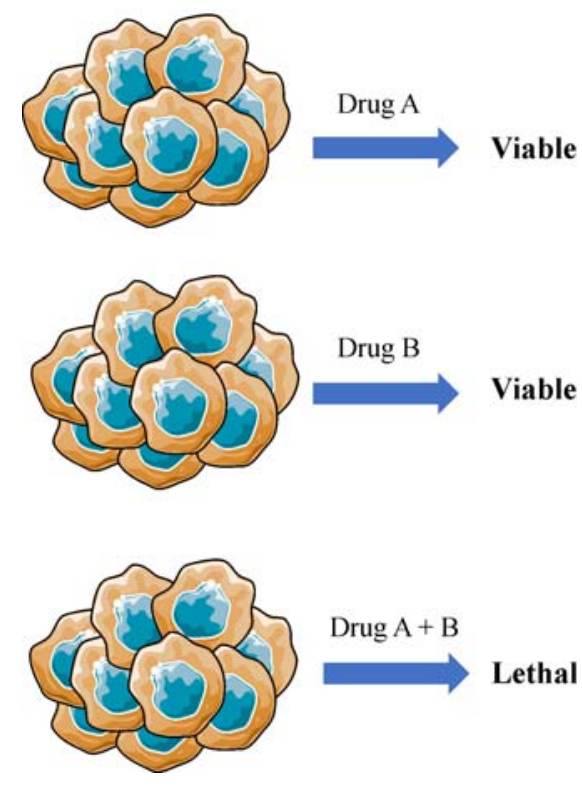

Fig. 1 Schematic outline of the concept of synthetic lethality. Synthetic lethality refers to a genetic principle in which the combination of two genetic perturbations is lethal, whereas each individually is not. In the example shown here, only the combination of drug A and drug B is lethal to the cell, making the combination of A and B synthetic lethal. genetic screens have been used to identify kinases whose suppression synergizes with BRAF inhibition in $B R A F$ mutant colon cancer. The combination of BRAF and EGFR inhibition identified in this genetic screen has already been proven successful in clinical studies, underscoring the utility of using this technology to find clinically useful drug combinations $[8,9]$.

\section{Taking advantage of drug resistance}

The proverb "if you can't beat them, join them" means that if your adversaries are stronger than you, it is better to join their side. In terms of cancer therapy resistance that translates into: if cancer drug resistance development is unavoidable, should we not focus on taking advantage of drug resistance rather than fighting it? It has already been recognized over 50 years that drug resistance of cancer cells can come at a fitness cost that in turn can cause sensitivity to other drugs, a situation referred to as "collateral sensitivity" [10]. For instance, upregulation of multidrug resistance pumps during acquisition of resistance to chemotherapy can cause oxidative stress through increased ATP consumption and glutathione depletion [11]. This in turn can lead to vulnerabilities that can be exploited therapeutically. Collateral sensitivity is widespread in biology, as also bacteria that develop resistance to antibiotics can acquire collateral sensitivity to other antibiotics [12]. A case in point is what happens when $B R A F$ mutant melanomas develop resistance to BRAF inhibitors. Clinical data show that melanoma patients that have developed resistance to BRAF inhibitors and whose therapy is discontinued show an initial stabilization or even a decline of the tumor rather than a disease flare up. This phenomenon is referred to as the "drug holiday effect" [13-15]. That a drug resistant tumor is stabilized by drug withdrawal suggests that drug resistant cells are at a disadvantage in the absence of drug. Indeed, in melanoma, drug withdrawal after acquisition of resistance to BRAF inhibitors has been shown to cause hallmarks of oncogeneinduced senescence due to hyperactivation of MAPkinase pathway signaling and points toward an acquired vulnerability of drug-resistant cells that was not present in the parental drug-sensitive cells [16]. This model implies that in melanoma, intermittent dosing may be more effective than continuous dosing, as the intermittent dosing alternates between providing an advantage to the drug sensitive and the drug resistant cells (Fig. 2). Indeed, in animal models of $B R A F$ mutant melanoma, an intermittent dosage with BRAF inhibitor resulted in longer disease control than continuous dosing [17]. Based on this concept, number of clinical trials have been conducted to study whether intermittent dosing leads to more durable response than continuous dosing in BRAF mutant melanoma patients with either a BRAF inhibitor LGX818 (NCT01894672, 

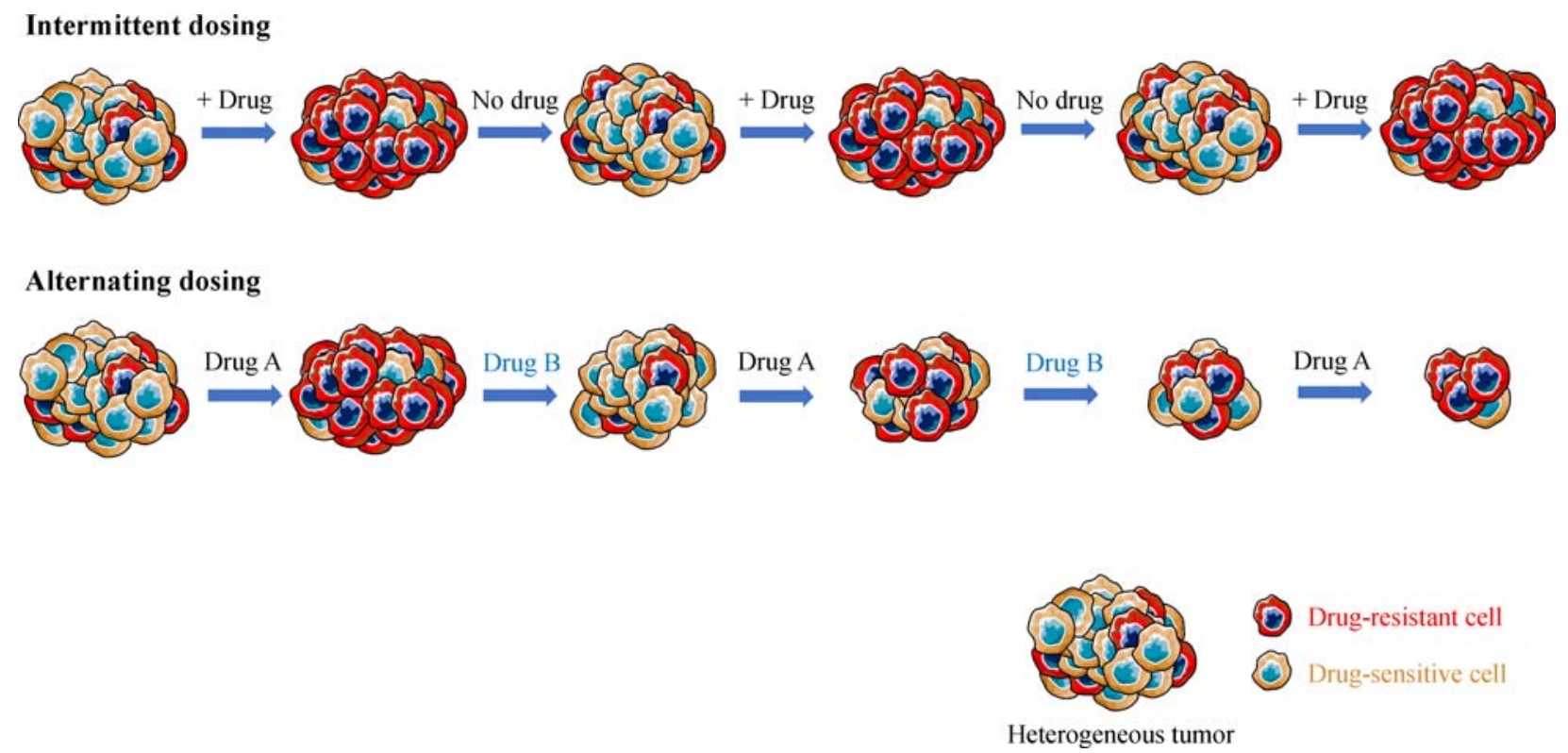

Fig. 2 Alternative drug administration schedules. Intermittent dosing uses regular "drug holidays" in which the patient is not exposed to drug. Cancer cells that have developed resistance to a cancer drug may be at a selective disadvantage in the absence of drug, leading to a decline in the fraction of drug resistant cells in this drug holiday. This should result in increased response when the drug is given again, as the fraction of drug sensitive cells should have increased during the drug holiday.

NCT02263898) or combination of BRAF inhibitor dabrafenib and MEK inhibitor trametinib (NCT02196181) [18].

Alternating dosing can be applied if a vulnerability of drug-resistant cells has been identified. After a first treatment with a given cancer drug, the drug-resistant cells can be selectively eliminated with a second drug, after which the population should be sensitive to the first drug again.

A number of recent studies have demonstrated induced collateral sensitivity in cancer cells that have acquired resistance to a number of targeted inhibitors or chemotherapy [19-21]. An improved version of an intermittent dosing approach to the treatment of drug resistant cancer could therefore be the use of a second drug that selectively targets the acquired vulnerability of the drug resistant cells (Fig. 2). In this model, the drug-resistant cells are actively killed by the second drug rather than being only at a disadvantage, as is the case in the intermittent dosing scenario. The alternating drug model should, at least in theory, therefore be more effective than the intermittent dosing.

But which are the vulnerabilities of drug resistant cells? As one example, it has recently been shown that cancer cells that become tolerant to a variety of cancer drugs adopt a mesenchymal cell state, which is associated with higher ROS levels compared to their parental drug-sensitive cells. The resistant cells are highly dependent on the lipid hydroperoxidase GPX4 to tolerate the high ROS level to survive. This specific dependency could be explored as a selective vulnerability of the drug-resistant cells. Indeed, these drugresistant cells were shown to be highly vulnerable to a GPX4 inhibitor, which caused a massive ROS induction leading to a non-apoptotic cell death called ferroptosis $[19,20]$.

\section{A one-two punch model for cancer therapy}

Our own recent data indicate that resistance to BRAF inhibitors in $B R A F$ mutant melanoma is associated with a significant increase in ROS levels [22]. Histone deacetylase inhibitors (HDACi) increase these already elevated levels of ROS further, leading to toxic ROS levels only in BRAF inhibitor resistant melanomas following treatment with HDACi. This acquired vulnerability of BRAF inhibitor resistant cells is thus a collateral sensitivity that can be exploited with a second drug that exploits the acquired vulnerability [22]. We have dubbed this sequential model for cancer therapy the "one-two punch" model [23]. Can this one-two punch model of sequential drug treatment be generalized to apply to all forms of cancer? We have shown recently that genetic screens can be used to identify compounds that induce senescence in cancer cells [23]. Senescent cells display a stable proliferation arrest, but remain viable. Importantly, their cellular state is quite distinct from that of proliferating cells [24]. For instance, senescent cells are distinct in terms of gene expression [25], chromatin structure [26] and metabolism [27,28]. 


\section{One-two punch model for cancer therapy}
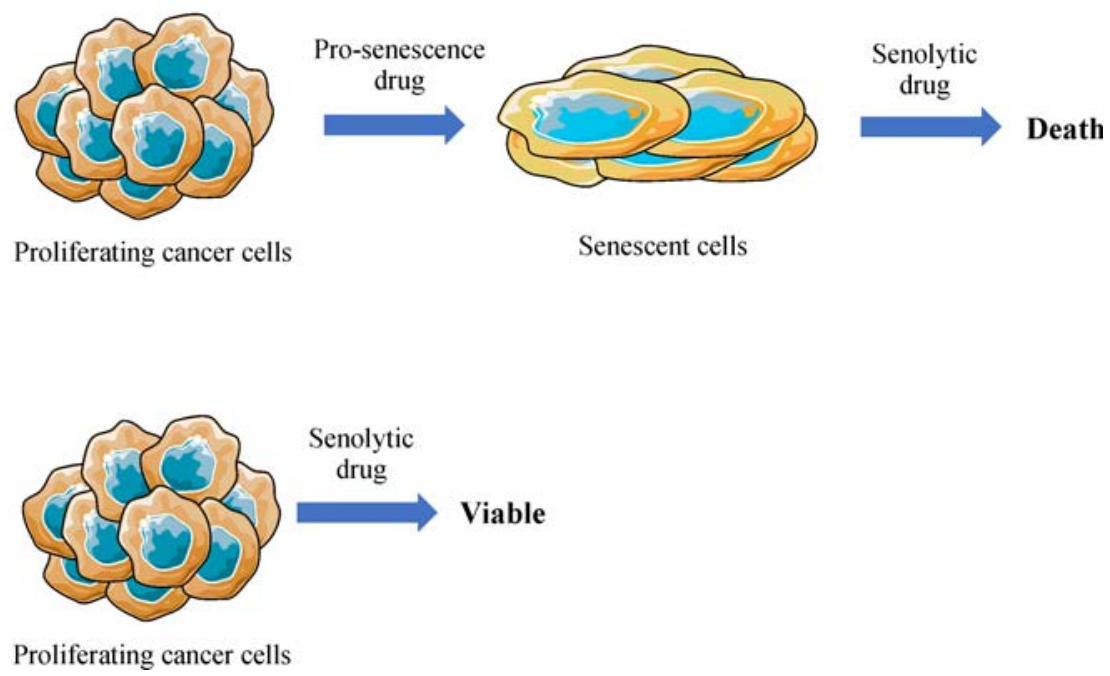

Fig. 3 A one-two punch model for cancer therapy. Pro-senescence drugs can be used to induce a stable proliferation arrest associated with the onset of senescence in cancer cells. A subsequent therapy with agents that kill senescent cells (senolytic drugs) can then be applied to selectively eradicate the senescent cancer cells. Note that the proliferating cancer cells are not sensitive to the senolytic agents, which makes a sequential (or concomitant) treatment schedule necessary.

This suggests that they might be sensitive to drugs that specifically target this acquired state and therefore do not kill their proliferating counterparts (Fig. 3). Indeed, ABT263, a specific inhibitor of anti-apoptotic proteins has been shown to selectively kill senescent cells in vivo $[29,30]$. This suggests that such so-called senolytic agents can also be used in a "one-two punch" consecutive therapy approach for cancer in which a first drug is used to induce senescence selectively in cancer cells and a subsequent senolytic therapy serves to eradicate the senescent cancer cells (Fig. 3). An important advantage of such a one-two punch therapy model is that drugs are not given in combination but sequentially, which allows for more drugs to be combined as sequential treatment avoids toxicity of simultaneous drug administration.

\section{Conclusions}

We must rethink how we use existing cancer drugs to optimize therapy responses. The knee-jerk reaction to dose all drugs to maximum tolerated dose and combine drugs haphazardly in the hope to find more effective drug combinations should no longer be used. We need to identify vulnerabilities of drug-resistant cancer cells and selectively target these acquired vulnerabilities. This strategy appears more appealing than fighting a losing battle against the inevitable development of drug resistance.

\section{Acknowledgements}

The work of the authors is supported by the Oncode Institute, which is financed in part by the Dutch Cancer Society (KWF) and by the gravitation program CancerGenomics.nl from the Netherlands Organisation for Scientific Research (NWO).

\section{Compliance with ethics guidelines}

Liqin Wang and Rene Bernards declare no competing or financial interests. This manuscript does not involve any research protocols requiring approval by the relevant ethical committee or institutional review board.

Open Access This article is distributed under the terms of the Creative Commons Attribution 4.0 International License (http:// creativecommons.org/licenses/by/4.0/), which permits unrestricted use, distribution, and reproduction in any medium, provided the appropriate credit is given to the original author(s) and the source, and a link is provided to the Creative Commons license, which indicates if changes are made.

\section{References}

1. Weinstein IB. Cancer. Addiction to oncogenes - the Achilles heal of cancer. Science 2002; 297(5578): 63-64

2. Sun C, Bernards R. Feedback and redundancy in receptor tyrosine kinase signaling: relevance to cancer therapies. Trends Biochem Sci 
2014; 39(10): 465-474

3. Flaherty KT, Puzanov I, Kim KB, Ribas A, McArthur GA, Sosman JA, O’Dwyer PJ, Lee RJ, Grippo JF, Nolop K, Chapman PB. Inhibition of mutated, activated BRAF in metastatic melanoma. N Engl J Med 2010; 363(9): 809-819

4. Flaherty KT, Robert C, Hersey P, Nathan P, Garbe C, Milhem M, Demidov LV, Hassel JC, Rutkowski P, Mohr P, Dummer R, Trefzer U, Larkin JM, Utikal J, Dreno B, Nyakas M, Middleton MR, Becker JC, Casey M, Sherman LJ, Wu FS, Ouellet D, Martin AM, Patel K, Schadendorf D; the METRIC Study Group. Improved survival with MEK inhibition in BRAF-mutated melanoma. N Engl J Med 2012; 367(2): 107-114

5. Long GV, Fung C, Menzies AM, Pupo GM, Carlino MS, Hyman J, Shahheydari H, Tembe V, Thompson JF, Saw RP, Howle J, Hayward NK, Johansson P, Scolyer RA, Kefford RF, Rizos H. Increased MAPK reactivation in early resistance to dabrafenib/ trametinib combination therapy of BRAF-mutant metastatic melanoma. Nat Commun 2014; 5(1): 5694

6. Kopetz S, Desai J, Chan E, Hecht JR, O’Dwyer PJ, Maru D, Morris V, Janku F, Dasari A, Chung W, Issa JP, Gibbs P, James B, Powis G, Nolop KB, Bhattacharya S, Saltz L. Phase II pilot study of vemurafenib in patients with metastatic BRAF-mutated colorectal cancer. J Clin Oncol 2015; 33(34): 4032-4038

7. Beijersbergen RL, Wessels LFA, Bernards R. Synthetic lethality in cancer therapeutics. Annu Rev Cancer Biol 2017; 1(1): 141-161

8. Prahallad A, Sun C, Huang S, Di Nicolantonio F, Salazar R, Zecchin D, Beijersbergen RL, Bardelli A, Bernards R. Unresponsiveness of colon cancer to BRAF(V600E) inhibition through feedback activation of EGFR. Nature 2012; 483(7387): 100-103

9. van Geel RMJM, Tabernero J, Elez E, Bendell JC, Spreafico A, Schuler M, Yoshino T, Delord JP, Yamada Y, Lolkema MP, Faris JE, Eskens FALM, Sharma S, Yaeger R, Lenz HJ, Wainberg ZA, Avsar E, Chatterjee A, Jaeger S, Tan E, Maharry K, Demuth T, Schellens JHM. A phase Ib dose-escalation study of encorafenib and cetuximab with or without alpelisib in metastatic $B R A F$-mutant colorectal cancer. Cancer Discov 2017; 7(6): 610-619

10. Hutchison DJ. Cross resistance and collateral sensitivity studies in cancer chemotherapy. In: Haddow A, Weinhouse S, editors. Advances in Cancer Research. 7: Academic Press; 1963. 235-350

11. Szakács G, Hall MD, Gottesman MM, Boumendjel A, Kachadourian R, Day BJ, Baubichon-Cortay H, Di Pietro A. Targeting the Achilles heel of multidrug-resistant cancer by exploiting the fitness cost of resistance. Chem Rev 2014; 114(11): 5753-5774

12. Imamovic L, Sommer MOA. Use of collateral sensitivity networks to design drug cycling protocols that avoid resistance development. Sci Transl Med 2013; 5(204):204ra132

13. Seghers AC, Wilgenhof S, Lebbé C, Neyns B. Successful rechallenge in two patients with BRAF-V600-mutant melanoma who experienced previous progression during treatment with a selective BRAF inhibitor. Melanoma Res 2012; 22(6): 466-472

14. McMahon M. Intermittent dosing in melanoma. Clin Adv Hematol Oncol 2015; 13(6): 348-350 PMID:26352888

15. Treiber N, Huber MA, Schneider LA, Scharffetter-Kochanek K, Schultz E, Debus D. Intermittent vemurafenib therapy in malignant melanoma. J Dtsch Dermatol Ges 2017; 15(4): 451-454

16. Sun C, Wang L, Huang S, Heynen GJJE, Prahallad A, Robert C, Haanen J, Blank C, Wesseling J, Willems SM, Zecchin D, Hobor S,
Bajpe PK, Lieftink C, Mateus C, Vagner S, Grernrum W, Hofland I, Schlicker A, Wessels LF, Beijersbergen RL, Bardelli A, Di Nicolantonio F, Eggermont AM, Bernards R. Reversible and adaptive resistance to $\mathrm{BRAF}(\mathrm{V} 600 \mathrm{E})$ inhibition in melanoma. Nature 2014; 508(7494): 118-122

17. Das Thakur M, Salangsang F, Landman AS, Sellers WR, Pryer NK, Levesque MP, Dummer R, McMahon M, Stuart DD. Modelling vemurafenib resistance in melanoma reveals a strategy to forestall drug resistance. Nature 2013; 494(7436): 251-255

18. Luke JJ, Flaherty KT, Ribas A, Long GV. Targeted agents and immunotherapies: optimizing outcomes in melanoma. Nat Rev Clin Oncol 2017; 14(8): 463-482

19. Hangauer MJ, Viswanathan VS, Ryan MJ, Bole D, Eaton JK, Matov A, Galeas J, Dhruv HD, Berens ME, Schreiber SL, McCormick F, McManus MT. Drug-tolerant persister cancer cells are vulnerable to GPX4 inhibition. Nature 2017; 551(7679): 247-250

20. Viswanathan VS, Ryan MJ, Dhruv HD, Gill S, Eichhoff OM, Seashore-Ludlow B, Kaffenberger SD, Eaton JK, Shimada K, Aguirre AJ, Viswanathan SR, Chattopadhyay S, Tamayo P, Yang WS, Rees MG, Chen S, Boskovic ZV, Javaid S, Huang C, Wu X, Tseng YY, Roider EM, Gao D, Cleary JM, Wolpin BM, Mesirov JP, Haber DA, Engelman JA, Boehm JS, Kotz JD, Hon CS, Chen Y, Hahn WC, Levesque MP, Doench JG, Berens ME, Shamji AF, Clemons PA, Stockwell BR, Schreiber SL. Dependency of a therapy-resistant state of cancer cells on a lipid peroxidase pathway. Nature 2017; 547(7664): 453-457

21. Zhao B, Sedlak JC, Srinivas R, Creixell P, Pritchard JR, Tidor B, Lauffenburger DA, Hemann MT. Exploiting temporal collateral sensitivity in tumor clonal evolution. Cell 2016; 165(1): 234-246

22. Wang L, Leite de Oliveira R, Huijberts S, Bosdriesz E, Pencheva N, Brunen D, Bosma A, Song JY, Zevenhoven J, Los-de Vries GT, Horlings H, Nuijen B, Beijnen JH, Schellens JHM, Bernards R. An acquired vulnerability of drug resistant melanoma with therapeutic potential. Cell 2018; 173(6): 1413-1425.e14

23. Wang L, Leite de Oliveira R, Wang C, Fernandes Neto JM, Mainardi S, Evers B, Lieftink C, Morris B, Jochems F, Willemsen L, Beijersbergen RL, Bernards R. High-throughput functional genetic and compound screens identify targets for senescence induction in cancer. Cell Reports 2017; 21(3): 773-783

24. Muñoz-Espín D, Serrano M. Cellular senescence: from physiology to pathology. Nat Rev Mol Cell Biol 2014; 15(7): 482-496

25. Fridman AL, Tainsky MA. Critical pathways in cellular senescence and immortalization revealed by gene expression profiling. Oncogene 2008; 27(46): 5975-5987

26. Narita M, Nũnez S, Heard E, Narita M, Lin AW, Hearn SA, Spector DL, Hannon GJ, Lowe SW. Rb-mediated heterochromatin formation and silencing of E2F target genes during cellular senescence. Cell 2003; 113(6): 703-716

27. Jiang $\mathrm{P}, \mathrm{Du} \mathrm{W}$, Mancuso A, Wellen KE, Yang X. Reciprocal regulation of $\mathrm{p} 53$ and malic enzymes modulates metabolism and senescence. Nature 2013; 493(7434): 689-693

28. Wiley CD, Campisi J. From ancient pathways to aging cellsconnecting metabolism and cellular senescence. Cell Metab 2016; 23(6): 1013-1021

29. Chang J, Wang Y, Shao L, Laberge RM, Demaria M, Campisi J, Janakiraman K, Sharpless NE, Ding S, Feng W, Luo Y, Wang X, 
Aykin-Burns N, Krager K, Ponnappan U, Hauer-Jensen M, Meng A, Zhou D. Clearance of senescent cells by ABT263 rejuvenates aged hematopoietic stem cells in mice. Nat Med 2016; 22(1): 78-83

30. Zhu Y, Tchkonia T, Fuhrmann-Stroissnigg H, Dai HM, Ling YY,
Stout MB, Pirtskhalava T, Giorgadze N, Johnson KO, Giles CB, Wren JD, Niedernhofer LJ, Robbins PD, Kirkland JL. Identification of a novel senolytic agent, navitoclax, targeting the Bcl-2 family of anti-apoptotic factors. Aging Cell 2016; 15(3): 428-435 